\title{
Clostridium tetani
}

National Cancer Institute

\section{Source}

National Cancer Institute. Clostridium tetani. NCI Thesaurus. Code C86298.

A species of anaerobic, Gram positive, rod shaped bacteria assigned to the phylum

Firmicutes. This species is motile by peritrichous flagella, indole and lipase positive,

lecithinase negative, hydrolyzes gelatin, ferments inositol and does not ferment glucose

or maltose. C. tetani may colonize the intestinal tract of humans and is pathogenic, being the causative agent of Tetanus infection. 